\title{
THE
}

\section{Propaganda in an Age of Algorithmic Personalization: Expanding Literacy Research and Practice}

Renee Hobbs

University of Rhode Island, hobbs@uri.edu

Follow this and additional works at: https://digitalcommons.uri.edu/com_facpubs

The University of Rhode Island Faculty have made this article openly available.

Please let us know how Open Access to this research benefits you.

This is a pre-publication author manuscript of the final, published article.

Terms of Use

This article is made available under the terms and conditions applicable towards Open Access

Policy Articles, as set forth in our Terms of Use.

\section{Citation/Publisher Attribution}

Hobbs, R. (2020). Propaganda in an Age of Algorithmic Personalization: Expanding Literacy Research and Practice. Reading Research Quarterly. https://doi.org/10.1002/rrq.301

Available at: https://doi.org/10.1002/rrq.301 


\title{
Propaganda in an Age of Algorithmic Personalization: Expanding Literacy Research and Practice
}

\author{
Renee Hobbs \\ University of Rhode Island \\ Harrington School of Communication and Media \\ Kingston RI USA 02882 \\ Email: hobbs@uri.edu \\ Accepted for publication in Reading Research Quarterly \\ December 27, 2019
}

CITE AS: Hobbs, R. (2020). Propaganda in an Age of Algorithmic Personalization:

Expanding Literacy Research and Practice. Reading Research Quarterly.

https://doi.org/10.1002/rrq.301

\begin{abstract}
This commentary considers the rise of algorithmic personalization and the power of propaganda as it is shifting our understanding of the landscape of 21st-century literacy research and practice. Algorithmic personalization uses data from the behaviors, beliefs, interests and emotions of the target audience to provide filtered digital content, targeted advertising, and differential product pricing to online users. Understanding the propaganda function of algorithmic personalization may lead to a deeper consideration of texts that activate emotion and tap into audience values for aesthetic, commercial and political purposes. As persuasive genres, advertising and propaganda may demand different types of reading practices than texts whose purpose is primarily informational or argumentative. Increased attention to algorithmic personalization, propaganda and persuasion in the context of K-12 literacy education may also help people cope with sponsored content, bots, and other forms of propaganda and persuasion that now circulate online.
\end{abstract}

Keywords: digital literacy, algorithms, personalization, propaganda, English language arts, education 
Like the term culture, literacy is a term whose meaning has expanded over time. During the 19th century, the term culture referred to refinements in taste associated with the attainment of social privilege, but by the 20th century, it came to be understood more broadly as the patterns of life that humans enact as part of ordinary social life (King, 2019). Similarly, while literacy is generally understood as the cognitive and social practices associated with the comprehension and use of print language, some educators and scholars are interested in conceptualizing literacy more broadly. The literacy education community has long recognized the relationship between literacy and culture and the potential of media and communication to transform educational structures and practices (New London Group, 1996).

The rise of the Internet has led scholars to conceptualize the practices of locating, accessing, creating and sharing content as literacy practices with relevance to work, life, and citizenship (Greenhow, Robelia \& Hughes, 2009). Today, people comprehend, interpret, and create many different types of media texts in daily life. While reading a novel, listening to a podcast, and watching a video are different social, cultural and cognitive practices, they are all forms of "reading" that involve decoding, comprehension, interpretation, and analysis (Hobbs, 2007; Hobbs, Deslauriers \& Steager, 2019). Composing a meme, creating a multimedia PowerPoint slide deck to summarize ideas, and making a podcast or documentary video are forms of "writing" that involve creative choices, authorial intent, design skills, and technical competencies (Hicks, 2018; Hobbs 2017). Because of the wide variety of media available for learners inside and outside of school, teachers often adapt instructional strategies used in reading print texts to help students use and comprehend multimodal texts (Moore \& Redmond, 2014). Literacy strategies including close reading and guided viewing strategies have been applied to listening to podcasts, viewing videos, and playing video games (Kozdras, Joseph, \& Schneider, 2015). As more researchers examine the distinctive social practices of digital literacy, calls for increased consensus are emerging in the definition of relevant concepts and terms in this increasingly complex field (Coiro, in press).

Despite these advances, many types of multimedia content continued to be undervalued in literacy education. While it was once a substantial part of English language arts education, the study of persuasion, propaganda and advertising has become increasingly uncommon in English language arts education (Fleming, 2019). Many forms of popular culture and mass media are considered "inappropriate" for critical analysis activities in the classroom (Moore, 2013) even though students bring substantial funds of knowledge from these texts into the school (Marsh, 2006). When students create videos to demonstrate their learning, educational leaders tend to perceive these activities as less valuable than other instructional strategies (Smythe, Toohey \& Dagenais, 2016). Even certain types of literature like romances, vampire stories, sports, horror, dystopian fiction, and fantasy are marginalized by schools (Smith, Wilhelm \& Fransen, 2016).

Given the plethora of digital content that young learners are exposed to that activates strong emotions, simplifies information, appeals to audience values, or attacks opponents in order influence people's attitudes and behaviors, it is ironic that American students get very little explosure to learn about advertising and propaganda in school (Hobbs, 2020). Since the rise of the so-called "fake news" crisis, some attention is now being directed at the competencies involved in evaluating the credibility of information sources (Breakstone et al, 2018). But we are just beginning to learn how everyday experiences with entertainment, information and 
persuasion are increasingly personalized to the unique behaviors and interests of an individual user based on "data exhaust" that is collected by digital platforms and devices (Zuboff, 2019)

Although the concept of algorithmic personalization was first popularized in 2011 by Eli Pariser, who described it as a filter bubble, public awareness grew significantly after U.S. presidential election in 2016, when public concerns about propaganda, disinformation and fake news were running high. At that time, several professional educational organizations responsible for teaching writing, composition and speech reaffirmed their commitment to teaching the responsible use of language as a form of social power. In 2019, the National Council of Teachers of English issued a resolution on critical literacy in English education, calling for educators to promote pedagogy and scholarly curricula in English and related subjects that instruct students in analyzing and evaluating "sophisticated persuasive techniques in all texts, genres, and types of media, current and yet to be imagined." They also urge members to (a) support classroom practices that examine and question uses of language in order to discern inhumane, misinformative, or dishonest discourse and arguments; (b) prioritize research and pedagogies that encourage students to become critical thinkers, consumers, and creators who advocate for and actively contribute to a better world; (c) provide resources to mitigate the effect of new technologies and platforms that accelerate and destabilize our information environment; (d) support the integration of reliable, balanced, and credible news sources within classroom practices at all levels of education; (e) resist attempts to influence civic discussion through falsehoods, unwarranted doubts, prejudicial or stereotypical ideas, attempts to shame or silence, or other techniques that deteriorate the quality of public deliberation; and (f) model civic literacy and conversation by creating a supportive environment where students can have an informed discussion and engage with current events and civic issues while staying mindful and critical of the difference between the intent and impact of their language (NCTE, 2019). Such important efforts will be more likely to thrive if literacy researchers create new knowledge that helps us understand how literacy practices may be applied effectively to the new forms of propaganda and algorithmic personalization that are part of daily life.

In this commentary, I examine how and why literacy scholars and educators must expand literacy practices to focus on algorithmic personalization and the persuasive genres that shape the quality of information and entertainment we receive. As data harvesting and surveillance become a more ubiquitous aspect of our everyday use of the Internet, algorithmic personalization can be conceptually understood as a new type of manipulation, with both potentially beneficial and harmful effects. Throughout the ages, skillful persuaders have tapped into people's pre-existing behaviors, beliefs and attitudes as a means to gain power, often without the awareness of those they influence. But today's English language arts educators rarely focus on persuasive genres in K-12 education because the study of argumentation has displaced attention to advertising and propaganda. Moreover, new forms of education propaganda are emerging which use a skillful blend of journalism and persuasion to depict the learning analytics associated with "personalized learning" as a panacea for the future of public education. The growth of such sponsored content in educational discourses may not be easily detected by educational leaders. In the pages below, I outline some important opportunities for literacy scholars and educators to help people of all ages build the competencies needed to respond to the many new persuasive genres that we encounter today. 


\section{UNDERSTANDING ALGORITHMIC PERSONALIZATION}

Most readers of Reading Research Quarterly will have noticed how online search has been transformed over just a period of ten years in ways the reflect the growing power of Alphabet, the parent company of Google. Google products and services are inreasingly designed to keep its many users within the Google orbit for as long as possible. Now, more than half of all searches begin and end with Google, bypassing the need for users to visit an independently authored website (Fishkin, 2019). By tracking and predicting users' behavior, a selection of choices of entertainment, information and persuasion can be presented in highly customized ways to individuals, affecting how they use the Internet. The spectacular rise of Google to control more than $90 \%$ of the search engine business and become one of the world's largest companies has drawn regulators' concerns about market dominance (Henrickson, 2019).

Policymakers emphasize that transparency, equity, and fairness are needed to prevent digital bias and discrimination (Coen, Paul, Vanegas, Lange \& Hans, 2016). Algorithmic personalization is part of what Shoshana Zuboff (2019) has termed "surveillance capitalism," the practice of translating human experience into data that can be used to make predictions about behavior. It has been part of our lives for just over a decade, as Google first began to personalize its search engine in 2009, using 57 variables from users' behavior to decide what results to display after users entered keywords. The field has advanced enormously as new forms of algorithmic personalization are now in development, using facial recognition to monitor emotions and sensors to track movements with new approaches to data mining and machine learning (Williamson, 2017).

As digital platforms have become a central feature of contemporary life, concerns have grown around their impact. There is widespread public concern about the use of sophisticated surveillance systems and policy debates about potential regulation have focused on the commodification of user data (Adler, 2011). Today, many of the technology devices we use are increasingly likely to "read" our emotions (Turow, 2017; Wu, 2016) via a smartwatch or a wearable device that monitors heart rate or movement. Voice-activated home assistants listen to sounds from the home and analyze tone of voice and vocabulary (Zuboff, 2019). When real-time emotion data is combined with user targeting, it is easy to imagine a near-term future when users could be "provided precisely the right fake news story or ad not only to suit their personality type and preferences but also to respond to their emotional status at that moment" (Sivek, 2018, p. 128). As a result, some critics believe that digital technologies are quickly evolving in ways that may create potentially dangerous assymmetries of power that require attention from activists, scholars, educators and the general public.

Today, algorithmic personalization is present nearly every time users use the Internet, shaping the offerings displayed for information, entertainment and persuasion. Three routine and common types of algorithmic personalization that people experience in everyday life include: (1) filtered search results, (2) targeted advertising, and (3) differential pricing (Coen, Paul, Vanegas, Lange \& Hans, 2016). Online shoppers who live in wealthy neighborhoods are offered products at different prices than those in less affluent ones (Turow, 2017). Search engines predict what kinds of advertising and digital content users will like and find valuable, presenting personalized results based on those expectations. In one study, researchers examined differences in Google search results for users who were logged into their Google accounts as compared with other users. Findings demonstrate that Google provides people with different results not only based on their geographic location. Depending on their previous online behaviors, some users are presented with mainstream information sources and others are presented with special interest 
media. Researchers conclude that if people want to read news that is radical, offbeat, or racist, Google will help them find it (Puschmann, 2017).

Digital platforms are carefully designed to be sticky, to keep people using digital devices for as long as possible. Personalized recommendations for entertainment, persuasion, and social media are a key part of a business strategy to make it more likely that people will use media for longer and longer periods, enabling companies to profit by selling audience attention to advertisers (Doxtdator, 2017). For example, YouTube offers a customized list of recommended videos after a single video is played and Amazon presents a steady stream of new choices based on a user's previous book and media purchases. Netflix collects data on the scrolling, viewing, rewinding and even binge-watching behaviors of users to offer its customized movie and TV program choices. Although Netflix has carved up the collection of films it makes available into more than 76,000 micro-genres to create the illusion of endless choices, only a tiny sliver of content is offered to individual users. Personalization on Netflix embodies the filter bubble paradox: as you provide more information to Netflix, the less likely it is that you will encounter films outside your comfort zone and the narrower your choice options will becom (Pariser, 2011). As one critic puts it, recommendation engines simply do not take into account "the unknowable, eclectic, and ever-changing process of individual taste formation" (Alexander, 2016, p. 90).

\section{Algorithmic Transparency, Agency and Ethics}

How might people's differential levels of knowledge about algorithmic personalization affect reading and writing practices regarding the use of search engines, digital entertainment platforms, and social media? In algorithmically curated environments, "consumers should know when companies present them with an apparently automated but in fact edited and controlled version of reality" (Tene \& Polonetsky, 2019, p. 131). To examine the level of public awareness and transparency regarding the practice of algorithmic personalization, Powers (2017) conducted intensive interviews with undergraduate students. He found that although most students were aware that user data was being collected about their online behavior, they were largely unaware of algorithmic personalization. For example, $60 \%$ of students believed that the same results would be presented if two users separately entered the same search terms for news at the same time on Google. Few students spontaneously mentioned the human judgments that go into programming algorithms. When asked about how platforms track user data to deliver personalized content, only $20 \%$ of students were aware that Facebook prioritizes certain posts and hides other posts from view.

In 2016, when Instagram began using algorithmic personalization, a small group of users expressed their strong discontent, launching a protest on Twitter using the hashtag \#RIPInstagram. Researchers examined the attitudes of those users, finding that their active opposition to the use of algorithmic personalization was generally perceived as a violation of personal autonomy. Other users felt their agency was compromised because algorithmic personalization benefits the market for advertising at the expense of user control (Skrubbeltrang, Grunnet, \& Tarp, 2017).

The study of algorithmic personalization is just beginning to be noticed on the radar screen among those with interests in digital literacy (Alexander, Adams Becker \& Cummins, 2016). Little is yet known about how algorithmic personalization may affect processes of reading comprehension, inquiry, or the development of students' research skills. In my educational practice, I have been exploring how to help undergraduate students understand how algorithmic 
personalization shapes users' online experiences with information. With my colleagues in Germany, we developed an activity that asked students to conduct searches on countries including Finland, the U.S. and Germany on the same day using their Google accounts. Students were asked to post screenshots of their results on a digital bulletin board. Upon examining the evidence their searches generated, students discovered important differences in the information sources that were presented to them. Despite their similar ages, demographics and geographic location, students' search engine results varied greatly. For some students, algorithmic searches resulted in exposure to low-quality information sources, while others were presented mainstream or high-quality news media sources. Through the comparison-contrast process, students inferred that their own search results were influenced by their previous activities online (Hobbs, SeyferthZapf, \& Grafe, 2018). As a result of this activity, students discovered that for some of them, poor-quality news sources and misinformation "aren't hidden away in the dark recesses of the Internet but show up right at the top of the search results" (Puschmann, 2017, p. 1).

Awareness of algorithmic personalization may be low among people of all ages. Some may even treat search engine results as a kind of magic, when it seems that Google "reads your mind." Many people intuitively think of search engines as neutral or objective. Researchers have found that users put considerable trust in the Google brand and have little concern about the manipulation of search engine results. One mixed-method study of first-year college writing students found that when using a search engine, students use the first position in the search results as the relevant criterion for evaluating trustworthiness (Hargittai, Fullerton, MenchenTrevino, \& Thomas, 2010). Other research has shown that Facebook users experience both surprise and anger when they learn about how their News Feeds are algorithmically curated. When close friends and family were not shown in their feeds, participants often attributed the missing stories to their friends' decisions to exclude them. They did not imagine that an algorithm was elevating some posts and suppressing others. It is noteworthy to point out, however, that researchers found that higher levels of algorithmic awareness led to more active engagement with Facebook and bolstered overall feelings of control (Eslami et al, 2015).

Is algorithmic personalization ethical? It has been argued that algorithmic personalization is a mutual process where both the user and the algorithm have the power to influence the other (Beer, 2009). But algorithms are created by people whose own biases may be embodied in the code they write. Researchers have documented numerous examples of data failures specific to people of color and women, showing how Google Search reinforces stereotypes of African American women and others (Noble, 2018). One researcher conducted more than 2,000 searches of racially associated personal names across two websites. When searching for people with first names DeShawn, Darnell, and Jermaine, online ads were suggestive of an arrest in $81 \%$ to $86 \%$ of name searches on one website. When searching for people with first names of Geoffrey, Jill, and Emma, only a small portion of ads was suggestive of an arrest. These ads appeared regardless of whether the named individual had an arrest record in the company's database (Sweeney, 2013). Racism in algorithmically presented results is often rooted in the process of machine learning methodology itself.

All forms of machine learning have bias because the data used to train an algorithm is inevitably an unrepresentative subset of content. Sometimes, algorithms pick up on discriminatory cultural associations that are found across big datasets on the open Internet. As a result, algorithms can expose and amplify gender, racial and other forms of bias in society (Phillips, 2018). This is why public policy researchers recognize that ethical "values are at the heart of discussions on algorithms and big data" as decisions are made about how data can be 
gathered, who can use data and how it can be used, how privacy and security can be protected, and how it can be used for decision-making (Andrews, 2019, p. 298).

Experts are using the themes of empowerment and protection to reflect upon the social, political and economic and cultural consequences of algorithmic personalization. In one Delphitype study of expert opinion, experts agreed that algorithms have many benefits to individuals and society. They may lead to greater insights into the world as predictive modeling and other data-driven approaches to problem-solving expand. At the same time, they acknowledged potential risks and harms, noting that human agency may be threatened if the algorithms used to manipulate human decision-making processes are not transparent. Even those who create algorithms cannot fully understand the machine learning mechanisms by which the decisions are reached (Rainie, Anderson \& Page, 2017).

Researchers who are interested in expanding the concept of literacy are indeed wellpoised to examine how algorithmic personalization affects digital literacy practices both inside the clasroom and in the the practices of everyday life outside of school. There are plenty of relevant research questions to study. For example, we should learn whether or how algorithmic personalization may affect the development of people's taste preferences in books, movies and musical selections. We should know how algorithmic personalization affects pre-service and practicing teachers as they search for and find online information resources for teaching and learning. Algorithmic personalization may also affect the formation of group affiliations and social identity in ways that affect literacy practices. Researchers could examine how both educators and learners gain knowledge of how their online habits are tracked and monetized, examining how such knowledge may affect literacy practices and technology usage.

What kinds of instructional strategies could be useful in helping to build awareness of algorithmic personalization? How may such competencies be embedded in English language arts and literacy education? Given the many different ways that algorithmic personalization affects people's lives online, it will be important to advance theoretical concepts and develop pedagogies that deepen our understanding of algorithmic personalization's potential impact on learning. One of the best places for literacy educators to focus their attention is on teaching and learning about persuasion and propaganda. That's because, like algorithmic personalization, persuasive genres explicitly tailor messages to specific groups of people in an intentional and strategic effort to change their minds. To be effective, persuasive genres require that authors carefully consider the pre-existing knowledge, feelings and thoughts of their audiences. As I will show in the next section, algorithmic personalization may be conceptualized as new type of propaganda for a digital age.

\section{TEACHING AND LEARNING ABOUT PROPAGANDA}

It's important to note that the concept of propaganda has expanded over time, just as the concepts of literacy and culture have. While it once referred only to the state-sponsored dissemination of untruth, today the term propaganda is used to describe many forms of expression and communication designed to manipulate public opinion by activating strong emotions, simplifying ideas and information, attacking opponents, and responding to the deepest hopes, fears and dreams of its target audiences (Luckert \& Bachrach, 2007). Today, propaganda operations can easily masquerade as entertainment or as news, given that they exist side-by-side on social media platforms (Napoli, 2018). Rhetoricians and communication scholars have documented the changing nuances of meanings of the term propaganda (Huckin, 2016), noting 
that the manipulation of strong emotion is a key feature of propaganda because of its power to compel attention (Zillmann, 2003). Propaganda can be an effective tool for demagogues who simplify information and appeal to audience interests, influencing them by commanding and colonizing human attention.

Although suspicion and concern about persuasive speech has long shaped both ancient and modern political thought, persuasion and propaganda are a crucial part of the democratic political process. When I aim to persuade, I try to change the minds of my readers and listeners by linking my position to their existing knowledge, feelings and beliefs. In doing so, I am both leading and following my audience. In contrast to reasoning and argument, which relies on the logical presentation of evidence, persuasion and propaganda must be highly responsive to the feelings, needs, and shared beliefs of particular audiences. For this reason, "partiality, passion, and even prejudice have a legitimate and often productive role to play in democratic deliberations" (Garsten, 2006, p. 5).

Today, propaganda is taking new forms that require particular vigilance among members of the literacy and education research community. The term computational propaganda has recently emerged to describe the varieties of propaganda that now circulate on digital networks, including bots that artificially amplify messages to make it appear that certain views are widely shared (Wooley \& Howard, 2019). Many Americans first learned of the negative consequences of computational propaganda in the 2016 US Presidential election campaign, which included not only covert intelligence operations and hacking by the Russian government, but also paid social media users and bots orchestrated from within Russia's Internet Research Agency. These social media posts reached over 100 million Americans in a deliberate attempt to undermine public faith in the democratic process. They were entertaining and emotionally resonant messages, strategically designed to denigrate presidential candidate Hillary Clinton by sowing division, confusion and apathy (Andrews, 2019). One writer explained, "Today we have democratized propaganda - anyone can use these strategies to hijack attention and promote a misleading narrative, a hyperbolic story, or an outrageous ideology — as long as it captures attention and makes a profit for advertisers" (Rose-Stockwell, 2017, p. 1). Because of the potential to manipulate public sentiment via algorithms that select for particular kinds of emotions, concerns about contemporary propaganda have become a "near-horizon problem that could rapidly dwarf the contemporary fake news problem" (Bakir \& McStay, 2018, p. 155).

Readers may be surprised to learn that the concepts of propaganda, persuasion, and advertising are nearly nonexistent in the scholarship published in Reading Research Quarterly. For example, a search conducted in December 2019 on the terms "advertising," "propaganda" and "persuasion" produced only one published result. It is peculiar that persuasion and propaganda, which are forms of cultural discourse so central to culture and society, have not yet been considered relevant to research scholars in language and literacy education. Perhaps the rise of academic hyperspecialization can explain this phenomenon, as researchers and scholars with interests in propaganda, persuasion and advertising are more likely to come from fields of media and communication, psychology, literary theory, cultural studies, and rhetoric and composition studies.

But scholars have recently demonstrated that the absence of attention to persuasion and propaganda in English language arts education is not solely due to academic silos and hierarchies. In his compelling historical and critical analysis which traces the "fear of persuasion" over the course of $20^{\text {th }}$ century scholarship in English language arts education, Fleming (2019) shows how persuasive genres were gradually included in the curricula of college 
writing programs as faculty embraced the revival of classical rhetoric. After 1990, however, a focus on argumentation led writing and composition scholars to ignore persuasive genres. According to Fleming, the Common Core State Standards (CCSS) reproduces those values, explicitly denigrating the art of persuasion while lionizing argumentation. Indeed, an "explicit bias" against persuasive genres is evident in the CCSS reading and writing standards (Fleming, 2019, p. 522). Moreoever, the document sets forward a binary opposition between the concepts of persuasion and argumentation, stating that persuasive writing may appeal to the credibility, character, or authority of the writer as well as appeal to the audience's self-interest, sense of identity, or emotions while argument convinces the audience because of the perceived merit and reasonableness of the claims, evidence and proofs. According to Fleming, this kind of framing substantially misrepresents the 2,000-year-old history of rhetorical scholarship on peruasion.

In analyzing examples of lesson plans and typical classroom practices, Fleming offers evidence to show the many substantial ways in which English language arts educators have privileged logos over pathos and ethos. Indeed, a generation of educators has been taught to position argumentation as uniquely "truth seeking" and thus superior to persuasion, which uses mere emotion and appeals to character as a (presumably unethical) form of influence. As a result, Fleming explains, "In one stroke, the key insight of Aristotelian rhetorical theory, that persuasive argument is a matter of ethos, pathos, and logos, is overturned, making argument in schools an exclusively "logical" affair and practically banishing writing that appeals to 'emotions' or "character."' (2019, p. 522).

Indeed, teachers of English language arts were far more likely to teach about advertising, persuasion and propaganda in 1949 than in 2019. In the years before World War II, the study of persuasion was a key component of English language arts education, but it has now largely disappeared from the elementary and secondary grades (Hobbs \& McGee, 2014). Today's educators keep discussions of propaganda comfortably in the past, exploring it when reading George Orwell's Animal Farm or Nineteen Eighty-Four. As one critic put it, "Propaganda is something most of us read about in history class and wondered how people were so easily duped" (Ali, 2018, 1).

Explicitly missing from the scholarly literature on literacy is the clear possibility that advertising and propaganda are texts that demand different types of critical reading practices than texts whose purpose is primarily informational. Studies that explore literacy practices associated with the comprehension and interpretation of advertising, propaganda and disinformation could play an important role in building this knowledge base. In other fields, some groundwork has been laid. For example, in the field of psychology, researchers found that misleading headlines can affect how readers interpret both news and editorial content. In reading news stories, the presence of a misleading headline weakened readers' ability to recall the article's details. Readers also found information easier to remember when it aligned with the framing provided by the headline. In opinion articles, a misleading headline significantly impaired readers' inference-making (Ecker, Lewandowsky, Chang \& Pillai, 2014).

Typical literacy standards in education claim that "educators should select works of fiction and nonfiction that instill in students a deep appreciation for art, beauty, and truth" (State of Massachusetts Department of Education, 2017, p. 16). It is assumed that literature and informational texts are the only types of text that meet this very traditional cultural standard. Instructional practices for close reading typically include: determining the central ideas or themes of a text, summarizing the key supporting details and ideas, and evaluating the argument and specific claims in a text, including the validity of the reasoning as well as the relevance and 
sufficiency of the evidence (Common Core State Standards, 2016). Unfortunately, no mention is made of competencies needed for interpreting persuasive genres: exploring how language or other symbolic forms activate strong feelings and emotions; examining how commercial products are strategically linked to particular emotions; considering the power of personal attack to undermine audience perceptions of people, events or actions; examining how people's cultural and social identities can be depicted in ways that align with the pre-existing values, beliefs and attitudes of a specified target audience; or understanding how algorithms and computercontrolled accounts may be used to spread false or inaccurate information or make some ideas seem as if they are popular and widespread beliefs.

It is particularly distressing that state literacy standards make no mention of the importance of helping children at the primary, elementary and middle school levels examine and analyze the forms of advertising, persuasion and propaganda that they experience in daily life. There is voluminous research evidence that identifies the developmental trajectory in children's ability to recognize and analyze advertising and other persuasive genres (Nelson, 2016; Young, 1990). The 2017 State of Massachusetts Standards for English Language Arts and Literacy assumes that only high school students need to analyze persuasive genres. This document makes only a single reference to the study of advertising in standards for students in Grades 11 and 12. The document mentions a unit on rhetorical analysis, where students are introduced to the terms ethos, logos, pathos, occasion, audience, and speaker. Students are supposed to use these concepts to deconstruct advertising for a product, ballot question, or political candidate. Then students are encouraged to analyze the speeches of Brutus and Marc Antony in Shakespeare's Julius Caesar as well as orations by Frederick Douglass and Coretta Scott King (State of Massachusetts Department of Education, 2017, p. 116). While it may be a valuable learning experience, for students nearing the end of their high school years, it is not adequate preparation for thriving in a world saturated with personalized advertising and digital propaganda. Careful study of persuasive genres should begin in the primary grades and continue across all grade levels.

The absence of attention to the genres of advertising, propaganda, and persuasion is also noteworthy in the practice literature of the field. In English Journal, a total of 13 publications include with word propaganda and nine publications include the word advertising in the title. However, only one of of these articles was published in the $21^{\text {st }}$ century. In the 2019 International Literacy Association (ILA) conference program, there were 53 uses of the word digital and 8 uses of the word argumentation, but not a single reference to persuasion, advertising or propaganda. The in-school marginalization of persuasive genres does a disservice to students, teachers and the larger society and culture. It leaves unchecked the vast and significant volume of commercial and political culture that students encounter outside of school. Literacy scholars and educators should explore how literacy practices related to persuasive genres can become a bigger part of literacy learning. They could examine how persuasive genres are comprehended and analyzed by teachers themselves, given that wide differences in meaning-making and interpretation of advertising have been found among adults (Morris, Gilpin, Lenos \& Hobbs, 2011). Those with interests in composition could examine how the experience of composing certain forms of propaganda and persuasion may affect how children and young people interpret these genres. The scholarship of teaching could be used to document emerging approaches to teaching and learning about people's emotional response to the new forms of advertising and propaganda in contemporary culture, including partisan news, sponsored content, clickbait, conspiracy theories, hoaxes, satire, and parody (Hobbs, 2020). Educators themselves must 
actively confront and resist the "fear of persuasion" that may have developed because of the "failures and perversions of persuasion in our society," by recognizing that persuasive genres, despite their limitations, are fundamental mechanisms for democratic societies to develop social consensus. Persuasive communication is an important way that people are induced to act together, and it also can help keep physical violence at bay "by humanizing conflict rather than suppressing it" (Fleming, 2019, p. 535).

Classroom lessons that lionize argumentation and demonize persuasion may lead people to devalue persuasion by inscribing a strict hierarchy of rhetorical forms. Labeling reasoning as good and emotion as bad atually denies the legitimate role of character and emotion in human judgment. In the real world, argumentation, persuasion, and propaganda are all woven together into a seamless mix of expression, communication, and advocacy (Hobbs, 2020). By using a rigid set of narrow definitions, students may end up concluding that media messages that activate strong feelings or simplify information have little value or cannot be trusted. Such pedagogical approaches may contribute to cynicism about public discourse, leading learners away from the practices of agency, caring, critical consciousness, persistence, and emancipation, the practices that enable literacy to be relevant to the social, political, and technological realities of contemporary life (Mihailidis, 2018).

Analyzing propaganda requires the use of educational strategies where learners get to evaluate messages in the context in which they are created and received. Repeated practice may be valuable in exploring the interplay between thought and feeling, including the consideration of content, form, context, interpretation, meaning, impact, and the consequences of expression and communication as understood by both authors and audiences. After all, critical analysis may reveal that, in some cases, propaganda can be both socially beneficial and truthful, as when public-service advertising (PSAs) urge people not to text and drive or when activist filmmakers create emotionally powerful films about global immigration and migration that aim to shift public opinion about the timeless flow of humans across borders due to changes in ecological and political climates (Hobbs, 2020).

Literacy scholars and educators should explore the ethical dimensions of persuasion and propaganda as students learn to identify how authors create messages that aim to influence hearts and minds while respecting (or disrespecting) the autonomy of the readers (Fleming, 2019).

Students can learn to identify forms of propaganda that they are free to accept or reject and those forms where coercion may be present. For example, biased search results from algorithmic personalization may be a type of coercive propaganda when people are unaware of how filtering has shaped content.

Because algorithmic personalization creates new forms of social reality that align seamlessly with a user's pre-existing values, it will be especially important to explore with learners how various online literacy practices may affect people's attitudes, beliefs and behavior without their awareness. When users search online, they may not be aware of how personal information is used to filter search results. The results presented to them become the "reality" they experience. Pedagogies that disrupt the various types of unreal realities that are presented online can help people distinguish between the dimensions of personalization that seem innovative and useful and those which may be unfair and discriminatory.

\section{Defamiliarization Pedagogies}

Could people gain greater awareness of agorithmic personalization through the artistic processes and pedagogies of defamiliarization? If the activation of emotion contributes to the feeling of deep immersion in the unreal realities of persuasive genres, the concept of 
defamiliarization describes various ways to gain critical distance from that immersion. Defamiliarization has long been of practical value to educators who recognize the power of the surreal as a means to disrupt ordinary reading processes. The term defamiliarization was first coined in 1917 by Viktor Shklovsky who aimed to distinguish poetic from practical language, noting how poetic use of language can wake up the senses, helping people to notice what they have taken for granted or automatically perceived (Crawford, 1984). Defamiliarization is a central concept in the 20th-century art theory, but when it is used as a social practice among activists it has sometimes been called détournement or culture jamming (Harold, 2007).

As an approach that both celebrates and critiques emotional response to reading, viewing and media use, defamiliarization is an artistic and educational practice that heightens pleasure while simultaneously problematizing it (Teo, 2014). Since both telling a story and understanding it depends on acts of interpretation that can be replete with confusion, incompleteness, and cloudiness, "doubtless we are more aware of our interpretive efforts when faced with textual or referential ambiguities" (Bruner, 1991, p. 9). Mitchell (2016) identifies how defamiliarization techniques were intentionally used in a videogame to undermine expectations about time, space and user control of movement and action, requiring the game player to "expend effort to figure out what was happening...prolonging of the process of perception that occurs when reading poetic language" (p. 10). Defamiliarization can create a reflective state of mind and deepen close reading practices. Through the slowing down of perception, readers generate questions and consider how expectations shape interpretation. By presenting something common or ordinary in an unfamiliar or strange way, people's perception of the familiar is altered, reframed and enhanced. Defamiliarization can be a kind of wake-up call that may disrupt the routine and automatic processing of information.

Literacy researchers and educators have explored the defamiliarization process as it affects teaching and learning. In Hong's (2019) ethnographic study of kindergarten poetry activities, children wrote a collaborative poem about an ordinary stapler, making a familiar workplace object seem quite exotic by generating language that compared the stapler to snapping crocodiles, sharks and hippos. As part of this creative process, children performed and enacted the movements of the stapler to generate a variety of words and ideas. The process of defamiliarizing an ordinary object helped make poetry writing accessible to children with different levels of English language and literacy proficiency by allowing them to use multiple modes beyond language to participate in, construct and experience meaning-making processes in new ways.

Working with pre-service teachers, French and Campbell (2019) used defamiliarization techniques in an exploration of the state of American education as part of a course on Disciplinary Literacies. The authors first helped students recognize conflicting perspectives on teachers' unions, charter schools, and standardized tests and then students engaged in a media literacy production activity where they used remix practices in digital video composition to generate critical analysis of the dominant discourses of public education. Defamiliarization pedagogies may promote feelings of wonder, awe, appreciation or even disgust. Questioning the reading and writing practices of daily life can be especially powerful when we take seriously the many different forms of expression associated with the commercialization of culture, education and society. Because algorithmic personalization and the commercial propaganda associated with it has now entered directly into the sphere of public education, I turn to explore this topic before concluding this essay. 


\section{ALGORITHMIC PERSONALIZATION IN EDUCATION}

Algorithmic personalization and propaganda are influencing curriculum and instruction in elementary, secondary and higher education. As states have turned to competency-based education that emphasizes measures of grade-level progress through iterative assessment and the demonstration of specific skills, an interest in personalized learning has risen. In the education sector, personalized learning may include a wide range of practices, including learner-centered classrooms, the use of learning management systems, and digitally adaptive "intelligent tutoring" that uses algorithmic personalization (Bulger, 2016).

Personalized digital learning has been found to be effective in some learning contexts. For example, using a mix of face-to-face and online learning experiences with pre-service teachers enables more active approaches to learning and may allow instructors to adjust to the needs of a variety of learners (Zawilinski, Richard \& Henry, 2016). Digital platforms designed for children ages 2 to 11 may provide useful recommendations for printed books, videos, films, games and apps (Kucirkova, 2019). Some platforms use algorithmic personalization by incorporating data including grade level, performance on proficiency assessment, or the number of incorrect tries to deliver a playlist of activities to each learner. In some platforms, teachers can add, upload and select choices on behalf of students; in others, lessons and content are proprietary and embedded in the program, and algorithms make choices for learners based on data points (Bulger, 2016). Intelligent tutoring systems may even be designed to detect users' emotions through cues in language and facial expressions. The opportunity to harvest highly valuable data from users' online behaviors is one reason why venture capitalists invested $\$ 1.45$ billion in digital technology firms that specialize in K-12 and higher education in 2018 (Wan, 2019). As a business strategy, it makes sense that educational publishing companies crave access to the significant volumes of data that result from learners actively interacting with digital platforms for teaching and learning.

Critiques of personalized learning generally revolve around the themes of privacy, privatization, learner agency, and the regimes of testing. Because personalized learning algorithms rely on proprietary software, important educational decisions are placed in the hands of software engineers, entrepreneurs and business leaders, who are not accountable to the public or the communities in which their platforms are used. Because data is so highly valued, these firms may adopt an approach to curriculum and pedagogy that limits students' agency (Boninger, Molnar \& Saldaña, 2019). When Kucirkova (2019) examined personalized recommendation systems for children's literature, she noted that children's choices in reading for pleasure might be negatively influenced by the design of some currently popular reading recommendation systems. When choices are made to be "too easy," children's sense of agency is reduced. One digital platform allows teachers to select books from a large book database and assign individual titles to individual children, as well as monitor children's engagement with the system. According to the designers, such recommendation systems can help avoid the problem of information overload, as they are built on the logic of a search engine. But such personalization may also minimize children's agency by restricting the child from contributing to the database. Kucirkova grounded her argument in social constructionism, which acknowledges the material, embodied and institutional aspect of human experience. Social constructionism posits that cognitive challenges are vital to children's children's self-discovery learning, which occurs as they construct their own content by directly manipulating tools. Only when reading recommendation systems provide opportunities for "self-discovery, experimentation, and 
development of abstract knowledge" will they be able to challenge and widen children's thinking (Kucirkova, 2019, p. 80).

Silicon Valley companies and philanthropists have invested billions in developing digital technologies and platforms to monitor and track student progress through prescribed curriculum content, offering displays of student data on a dashboard for teachers, administrators, and parents (Williamson, 2015). Advances in algorithms that detect emotion are valued in the learning sciences. There, emotion analytics are used as a way to assess a learner's pedagogical and socioemotional wellbeing. Using facial recognition technologies, computer scientists are aiming to sense the emotional states of learners and then provide feedback or intervene in the learning process (Suero Montero, \& Suhonen, 2014).

Indeed, in their current form, data-driven instructional systems are seen by some as the future of education. But critics see them as representing a dystopian technological shift that reshapes schools and schooling by privileging interaction with machines over human social relationships. Scholars note that "digital technologies are not simply technical solutions to enhancing the quality, efficiency and effectiveness of practices, but can also be powerful valueembedded socio-technical interventions in the attempted shapings of practices, accountabilities and responsibilities" (Fenwick \& Edwards, 2016, p. 120). Some teachers already see the impact of this technological shift. Instead of liberating curricula, data-driven instructional systems imprison learners. Instead of providing tools for students to construct complex, dynamic representations of their learning, classroom teachers are forced to spend more and more time on monitoring, evaluation and testing than on teaching and learning (Halverson \& Smith, 2009).

American scholars and educational leaders should reflect on how we ourselves are subject to a considerable amount of propaganda about the potential of algorithms and personalized learning to transform education. Indeed, in the arena of educational technology, it can be sometimes difficult to distinguish between scholarship, journalism, and propaganda. Among the many examples of propaganda masquerading as a literature review is an article from an influential education website that publishes articles on personalized learning. The 74 Million is a sponsored magazine, a type of education propaganda that embeds the point of view of its funders into news and journalism about the profession of education. The website is supported by funding from foundations, corporate sponsors, and individuals. Although sponsored content stories generally include a disclosure of the funding source, they are easy to overlook. For example, one article on personalized learning purports to strike a middle ground between supporters and skeptics by presenting "facts, often overlooked, that could form the basis for a more balanced and rigorous conversation" (Rabbitt, 2017 as quoted in Doxtdator, 2017, p. 1). Although personalized learning is presented as a challenge to standardized testing, this article caricatures education as stuck in some factory model past, reproducing the educational technology industry's typical propaganda about the problems of education (Watters, 2015). Using Herman and Chomsky's (1989) five filter model of news as propaganda, Doxtdator (2017) shows how this particular article's neoliberal biases are carefully constructed to appeal to the pre-existing beliefs of the website's funders. He notes that the 74 Million is funded by the Gates Foundation, the Walton Foundation, and the current U.S. Department of Education Secretary, Betsy DeVos.

EdSurge, a similar sponsored content magazine that offers education propaganda to school leaders, was recently acquired by the International Society for Technology in Education (ISTE). It is subsidized by the Bill \& Melinda Gates Foundation, the Chan Zuckerberg Initiative, and the Susan and Michael Dell Foundation. EdSurge creates online sponsored content on behalf 
of advertisers in conjunction with its marketing team and also publishes content produced by advertisers themselves. When EdSurge produced an article on the role of emotive computing in the classroom, they showcased the many values of emotionally intelligent computing systems that deliver highly personalized content that adapts to individual differences in emotions. According to the article, emotion learning analytics involves monitoring learners' feelings in real-time. Not mentioned in the article is the point of view of critics, who say that such practices violate privacy and could amount to social control mechanisms that enable "people's attention, sentiments, and desires to be attuned to dominant political and commercial priorities," eroding capacities of reason and decision-making central to self-governance (Lewis, 2017 as quoted in Williamson, 2017, p. 284). Given the rise of sponsored content expressly designed to influence the beliefs, attitudes and behaviors of education leaders and policymakers, everyone in the field of education would be well-served by increased opportunities to identify, analyze, discuss, and reflect upon the many new types of propaganda they receive concerning the future of education.

\section{CONCLUSION}

Algorithmic personalization and contemporary propaganda are pervasive components of contemporary society that carefully target audiences with messages that align with people's preexisting beliefs, attitudes and values. Merely by interacting with friends and family, people release hundreds of megabytes of data to digital platforms with little understanding of how it will be used to persuade and manipulate them. Every day, students are swimming in a sea filled with advertising and promotion that offer them compelling visions of a consumer culture that's targeted just for them.

Educators should seek to balance the need to protect young people from the risks and potential harms of personalized propaganda with an emphasis on empowering them with a nuanced appreciation of how algorithmic personalization and propaganda may benefit individuals and societies. Of course, it is to be expected that some educators may choose merely to demonize platform companies and deride algorithmic personalization, while other educators will not want to rain on the parade of the beautiful array of new digital technologies that people now expect and treasure. As one high school English teacher in Maryland, put it, "Young people love advertising, consuming, entertainment, and technology. If we attack these trappings of modern life, we risk nurturing defensiveness" (Wilkinson, 2010, p. 24).

But I am confident that literacy educators and scholars can address the rise of algorithmic personalization and propaganda with a sufficient level of balance and nuance. Fortunately, inquiry learning practices enculturate people to the values of critical thinking, open-mindedness and epistemic humility, as learners discover the dangers of "gullibility, close-mindedness, intellectual arrogance, and wishful thinking," and "respect the role of emotion as part of our response to the world and of our lived experiences of it" (Bowell, 2017, p. 585). For such pedagogies to be impactful, research on literacy practices that examine the often-intense emotional responses we experience when encountering persuasive genres of digital media will be important.

As people gain more knowledge of how choice is structured by algorithms, they may find creative ways to play with algorithmic power, using it to their own advantage. One scholar explained that "as users begin to see how the information that they provide in the form of content impacts on the constitution of their life-worlds, so they may begin to actively shape the information so as to direct the way that the software reacts to them" (Beer, 2009, p. 997). 
Similarly, as learners get multiple, sustained opportunities to examine, analyze and practice the art of persuasion, they gain power in using language and communication to effect change in the social realm. Indeed, this is part of our birthright as citizens in a democracy.

Educators play a key role in helping people develop new knowledge and competencies that are relevant to contemporary life. Consider the potential of taking one simple project-based learning activity, the creation of a public service announcement, and more explicitly framing it as a means to learn about algorithmic personalization and contemporary propaganda. Close reading practices could help learners intentionally slow down to identify the author, purpose and point of view of a public service announcement. Even young learners could learn to recognize the oversimplification and stereotypes that are common in PSAs. Through creating and sharing PSAs online, students could notice how their own creative work may be more or less findable by different users, depending upon the kinds of metadata they add when sharing it. Such learning activities may give young learners opportunities to reflect on both the power and ethical responsibilities of computer science and the persuasive arts. These fundamental digital and media literacy practices are not yet normative in American public schools, but they could be.

The efforts of literacy researchers who have already helped to expand the concept of literacy will be needed to build an evidence base that supports best practices in the field. Such approaches to literacy education will need to be mindful of the value of building foundational knowledge for educators, who themselves need opportunities for professional learning on these topics. Members of the literacy research community should embrace the careful and systematic study of literacy practices associated with algorithmic personalization and persuasive genres so that they are no longer neglected concepts in literacy education.

\section{REFERENCES}

Adler, J. (2011). The public's burden in a digital age: Pressures on intermediaries and the privatization of Internet censorship. Journal of Law \& Policy, 20, $231-265$.

Alexander, N. (2016). Catered to your future self: Netflix's predictive personalization and the mathematization of taste. In K. McDonald and D. Smith-Rowsey (Eds.), The Netflix effect: Technology and entertainment in the $21^{\text {st }}$ century (pp. 81-97). New York: Bloomsbury Academic.

Alexander, B., Adams Becker, S., and Cummins, M. (2016). Digital Literacy: An NMC Horizon Project Strategic Brief. Volume 3.3. Austin, Texas: The New Media Consortium. Retrieved from https://library.educause.edu/ /media/files/library/2016/6/2016stratbriefdigitalliteracy.pdf

Ali, L. (2018, November 16). Why the P-word - propaganda - might be best for what we're seeing on our TV screens. Los Angeles Times. Retrieved from https://www.latimes.com/entertainment/tv/la-et-st-propaganda-fake-news-tv-culture20181116-story.html

Andrews, L. (2019). Public administration, public leadership and the construction of public value in the age of the algorithm and 'big data.' Public Administration, 97(2), 296-310. https://doi.org/10.1111/padm.12534

Bakir, V., \& McStay, A. (2018). Fake news and the economy of emotions: Problems, causes, solutions. Digital Journalism, 6(2), 154-175. https://doi.org/10.1080/21670811.2017.1345645 
Beer, D. (2009). Power through the algorithm? Participatory Web culture and the technological unconscious. New Media \& Society, 11(6), 985-1,002. http://dx.doi.org/10.1177/1461444809336551

Boninger, F., Molnar, A., \& Saldaña, C.M. (2019). Personalized Learning and the Digital Privatization of Curriculum and Teaching. Boulder, CO: National Education Policy Center. Retrieved from http://nepc.colorado.edu/publication/personalized-learning

Bowell, T. (2017). Response to the editorial 'Education in a post-truth world.' Educational Philosophy and Theory, 49(6), 582-585. https://doi.org/10.1080/00131857.2017.1288805

Breakstone, J., McGrew, S., Smith, M., Ortega, T., \& Wineburg, S. (2018). Teaching students to navigate the online landscape. Social Education, 82(4), 219-221.

Bruner, J. (1991). The narrative construction of reality. Critical Inquiry, 18(1), 1-21.

Bulger, M. (2016). Personalized Learning: The Conversations We're Not Having. Working Paper. New York: Data and Society.

Coen, R., Paul. E., Vanegas, P., Lange, A. and Hans, G. (2016, May 6). A User Centered Perspective on Algorithmic Personalization. Center for Democracy \& Technology. Master of Information Management and Systems: Final Project School of Information University of California, Berkeley. Retrieved from https://ctsp.berkeley.edu/usercentered-perspective-on-personalization/

Coiro, J. (in press). Working toward a multifaceted heuristic of print and digital reading to inform assessment, research, and practice. Manuscript submitted to Reading Research Quarterly.

Common Core State Standards (2016). Retrieved from http://www.corestandards.org/

Crawford, L. (1984) Viktor Shklovskij: Différance in defamiliarization. Comparative Literature 36, 209-219. https://www.jstor.org/stable/1770260

Doxtdator, B. (2017, December 16). The propaganda behind personalized learning. Long View on Education. https://www.longviewoneducation.org/propaganda-behind-personalisedlearning/

Ecker, U., Lewandowsky, S., Chang, E., \& Pillai, R. (2014). The effects of subtle misinformation in news headlines. Journal of Experimental Psychology: Applied, 20(4), 323-

335. https://doi.org/10.1037/xap0000028

Eslami, M., Rickman, A., Vaccaro, K., Aleyasen, A., Vuong, A., Karahalios, K. G., ... Sandvig, C. (2015). "I always assumed that I wasn't really that close to [her]": Reasoning about invisible algorithms in news feeds. In CHI 2015 - Proceedings of the 33rd Annual CHI Conference on Human Factors in Computing Systems: Crossings (pp. 153-162). (Conference on Human Factors in Computing Systems - Proceedings; Vol. 2015-April). Association for Computing Machinery. https://doi.org/10.1145/2702123.2702556

Fenwick, T., \& Edwards, R. (2016). Exploring the impact of digital technologies on professional responsibilities and education. European Educational Research Journal, 15(1), 117-131. https://doi.org/10.1177/1474904115608387

Fishkin, R. (2019, August 13). Less than half of Google searches now result in a click. Sparktoro. Retrieved from https://sparktoro.com/blog/less-than-half-of-google-searchesnow-result-in-a-click/

Fleming, D. (2019). Fear of persuasion in the English language arts. College English, 81(6), 508541. 
French, S. \& Campbell, J. (2019) Media literacy and American education: An exploration with détournement. Journal of Media Literacy Education, 11(1), 75 - 96. https://doi.org/10.23860/JMLE-2019-11-1-4

Garsten, B. (2006). Saving persuasion. Cambridge, MA: Harvard University Press.

Greenhow, C., Robelia, B., \& Hughes, J. E. (2009). Learning, teaching, and scholarship in a digital age: Web 2.0 and classroom research: What path should we take now? Educational Researcher, 38(4), 246-259. https://doi.org/10.3102/0013189X09336671

Halverson, R. and Smith, A. (2009). How new technologies have (and have not) changed teaching and learning in schools. Journal of Computing in Teacher Education 26(2), 4954.

Hargittai, E., Fullerton, L., Menchen-Trevino, E., \& Thomas, K. Y. (2010). Trust online: Young adults' evaluation of web content. International Journal of Communication, 4, $468-494$.

Harold, C. (2007). Our space: Resisting the corporate control of culture. Minneapolis: University of Minnesota Press.

Henrickson, J. (2019). Antitrust and the intrinsic value of Alphabet. Financial Times. Retrieved from https://ftalphaville.ft.com/2019/10/31/1572528791000/Antitrust-andthe-intrinsic-value-of-Alphabet/

Herman, E. \& Chomsky, N. (1989). Manufacturing consent: The political economy of the mass media. New York: Pantheon.

Hicks, T. (2018). The next decade of digital writing. Voices from the Middle, 25(4), 9-14.

Hobbs, R. (2020). Mind over media: Propaganda education for a digital age. New York: W.W. Norton.

Hobbs R. (2017). Create to learn: Introduction to digital literacy. New York: Wiley.

Hobbs, R. (2007). Reading the media: Media literacy in high school English. New York: Teachers College Press.

Hobbs, R., Deslauriers, E. \& Steager, P. (2019). The library screen scene: Film and media literacy in school, public and academic libraries. New York: Oxford University Press.

Hobbs, R. \& McGee, S. (2014). Teaching about propaganda: An examination of the historical roots of media literacy. Journal of Media Literacy Education 6(2), 56 - 67. https://doi.org/10.23860/JMLE-2016-06-02-5

Hobbs, R., Seyferth-Zapf, C. \& Grafe, S. (2018) Using virtual exchange to advance media literacy competencies through analysis of contemporary propaganda. Journal of Media Literacy Education, 10(2), 152 -168. https://doi.org/10.23860/JMLE-2018-10-2-9

Hong, H. (2019). Writing as defamiliarization processes: An alternative approach to understanding aesthetic experience in young children's poetry writing. Journal of Early Childhood Literacy, 19(2), 175-205. https://doi.org/10.1177/1468798417712338

Huckin, T. (2016). Propaganda defined. In G. Henderson \& M. Braun, (Eds.), Propaganda and rhetoric in democracy: History, theory, analysis. (pp. 118-136). Carbondale, IL: Southern Illinois University Press.

King, C. (2019). Gods of the upper air. New York: Doubleday.

Kozdras, D., Joseph, C., \& Schneider, J. J. (2015). Reading games: Close viewing and guided playing of multimedia texts. The Reading Teacher, 69(3), 331-338. https://doi.org/10.1002/trtr.1413 
Kucirkova, N. (2019). The learning value of personalization in children's reading recommendation systems: what can we learn from constructionism? International Journal of Mobile and Blended Learning (IJMBL), 11(4), 1-16. https://doi.org/10.4018/IJMBL.2019100106

Luckert, S. \& Bachrach, S. (2009). The state of deception: The power of Nazi propaganda. New York: W.W. Norton.

Marsh, J. (2006) Emergent media literacy: Digital animation in early childhood. Language and Education, 20(6), 493-506. https://doi.org/10.2167/le660.0

Mihailidis, P. (2018). Civic media literacies: Re-imagining engagement for civic intentionality. Learning, Media and Technology, 43(2), 152-164. https://doi.org/10.1080/17439884.2018.1428623

Mitchell, A. (2016, August 1-6). Making the familiar unfamiliar: Techniques for creating poetic gameplay. Paper presented at the 1st International Joint Conference of DiGRA and FDG. Retrieved from http://www.digra.org/wp-content/uploads/digital-library/paper_272.pdf

Morris, N., Gilpin, D. R., Lenos, M., \& Hobbs, R. (2011). Interpretations of cigarette advertisement warning labels by Philadelphia Puerto Ricans. Journal of Health Communication, 16(8), 908-922. https://doi.org/10.1080/10810730.2011.561910

Moore, D. C. (2013). Bringing the world to school: Integrating news and media literacy in elementary classrooms. Journal of Media Literacy Education, 5(1), 326 - 336.

Moore, D.C., \& Redmond, T. (2014). Media at the core: How media literacy strategies strengthen Common Core. Voices From the Middle, 21(4), 10- 15.

Napoli, P. M. (2018). What if more speech is no longer the solution? First Amendment theory meets fake news and the filter bubble. Federal Communications Law Journal, 70(1), 55 104.

National Council of Teachers of English (2019). Resolution on English Education for Critical Literacy in Politics and Media. Retrieved from http://www2.ncte.org/statement/resolution-english-education-critical-literacy-politics$\underline{\text { media/ }}$

Nelson, M.R. (2016) Developing persuasion knowledge by teaching advertising literacy in primary school. Journal of Advertising, 45(2), 169-182. https://doi.org/10.1080/00913367.2015.1107871

New London Group. (1996). A pedagogy of multiliteracies: Designing social futures. Harvard Educational Review, 66, 60-92. https://doi.org/10.17763/haer.66.1.17370n67v22j160u

Noble, S. (2018). Algorithms of oppression: How search engines reproduce racism. New York University Press.

Pariser, E. (2011). The filter bubble: What the Internet is hiding from you. London: Penguin UK.

Phillips, W. (2018). The Oxygen of Amplification. New York: Data \& Society Research Institute. Retrieved from https://datasociety.net/wp-content/uploads/2018/05/2-PART2_Oxygen_of_Amplification_DS.pdf

Powers, E. (2017). My news feed is filtered? Awareness of news personalization among college students. Digital Journalism, 5(10), 1315-1335. https://doi.org/10.1080/21670811.2017.1286943

Puschmann, C. (2019). How significant is algorithmic personalization in searches for political parties and candidates? Hans Bredlow Institute, Germany. Retrieved from https://aps.hans-bredow-institut.de/personalization-google/ 
Rainie, L., Anderson, J., \& Page, D. (2017). Code-dependent: Pros and cons of the algorithm age. Washington, D.C.: Pew Research Center.

Rose-Stockwell, T. (2017, July 14). This is how your fear and outrage are being sold for profit. Medium. Retrieved from https://medium.com/@tobiasrose/the-enemy-in-our-feedse86511488de

Skrubbeltrang, M. M., Grunnet, J., \& Tarp, N. T. (2017). \#RIPINSTAGRAM: Examining users' counter-narratives opposing the introduction of algorithmic personalization on Instagram. First Monday, 22(4). https://doi.org/10.5210/fm.v22i4.7574

Sivek, S. (2018). Both facts and feelings: Emotion and news literacy. Journal of Media Literacy Education, 10(2), 123 -138. https://doi.org/10.23860/JMLE-2018-10-2-7

Smith, M. W., Wilhelm, J., \& Fransen, S. (2016). The power of fostering pleasure in reading. In D. Appleman \& K. Hinchman (Eds). Adolescent literacy: A handbook of practice-based research (pp. 169 - 181). New York: Guilford Press.

Smythe, S., Toohey, K., \& Dagenais, D. (2016). Video making, production pedagogies, and educational policy. Educational Policy, 30(5), 740-770. https://doi.org/10.1177/0895904814550078

State of Massachusetts Department of Education (2017). Standards for English Language Arts and Literacy. Retrieved from http://www.doe.mass.edu/frameworks/ela/2017-06.pdf

Suero Montero, C., \& Suhonen, J. (2014). Proceedings of the 14th Koli Calling International Conference on computing education research (Vol. 2014, Koli Calling '14). ACM.

Sweeney, L. (2013). Discrimination in online ad delivery. Communications of the ACM, 56(5), 44-54. https://doi.org/10.1145/2447976.2447990

Taithe, B., \& Thornton, T. (1999). Propaganda: A misnomer of rhetoric and persuasion? In B. Taithe and T. Thorton (Eds), Propaganda: Political rhetoric and identity 1300-2000, (pp.1-24). Phoenix (UK): Sutton.

Tene, O., \& Polonetsky, J. (2017). Taming the Golem: Challenges of ethical algorithmic decision-making. North Carolina Journal of Law and Technology, 19, 125 - 172.

Teo, P. (2014). Making the familiar strange and the strange familiar: A project for teaching critical reading and writing. Language and Education 28(6), 1-13. https://doi.org/10.1080/09500782.2014.921191

Turow, J. (2017). The aisles have eyes: How retailers track your shopping, strip your privacy, and define your power. New Haven, CT: Yale University Press.

Wan, T. (2019 January 15). US edtech investments peak again with \$1.45 billion raised in 2018. EdSurge. Retrieved from https://www.edsurge.com/news/2019-01-15-us-edtechinvestments-peak-again-with-1-45-billion-raised-in-2018

Watters, A. (2015). The history of the future of education. Hack Education. Retrieved from http://hackeducation.com/2015/02/19/the-history-of-the-future-of-education

Wilkinson, R. (2010). Teaching dystopian literature to a consumer class. English Journal, 99(3), 22-26.

Williamson, B. (2017). Moulding student emotions through computational psychology: affective learning technologies and algorithmic governance, Educational Media International, 54(4), 267-288. https://doi.org/10.1080/09523987.2017.1407080

Williamson, B. (2015, December 10). Smarter learning software: Education and the big data imaginary. Paper presentation, Big Data-Social Data conference, University of Warwick. Retrieved from 
https://dspace.stir.ac.uk/bitstream/1893/22743/1/Smarter_learning_software_education_ and.pdf

Wooley, S. \& Howard, P. (2019). Computational propaganda: Political parties, politicians and political manipulation on social media. New York: Oxford University Press.

$\mathrm{Wu}, \mathrm{T}$. (2016). The attention merchants. New York: Vintage.

Young, B. M. (1990). Television advertising and children. Oxford: Clarendon Press.

Zawilinski, L. M., Richard, K. A., \& Henry, L. A. (2016). Inverting instruction in literacy methods courses: Making learning more active and personalized. Journal of Adolescent \& Adult Literacy, 59(6), 695-708. https://doi.org/10.1002/jaal.498

Zillmann, D. (2003). Theory of affective dynamics: Emotions and moods. In J. Bryant, D. Roskos-Ewoldsen, \& J. Cantor (Eds.) Communication and emotion: Essays in honor of Dolf Zillmann (pp. 533-567). Mahwah, NJ, US: Lawrence Erlbaum Associates Publishers.

Zuboff, S. (2019). The age of surveillance capitalism: The fight for a human future at the new frontier of power. New York: Profile Books.

RENEE HOBBS is professor of communication studies and director of the Media Education Lab at the Harrington School of Communication and Media at the University of Rhode Island, USA, where she co-directs the Graduate Certificate in Digital Literacy. Email: hobbs@uri.edu. 